\title{
O FETICHISMO DO CAPITAL PORTADOR DE JUROS
}

\author{
Mailson Bruno de Queiroz Carneiro Gonçalves ${ }^{1}$ \\ Eduardo Ferreira Chagas ${ }^{2}$
}

\begin{abstract}
Resumo:
O objetivo deste artigo é demonstrar como o capital portador de juros aparece na superfície da economia capitalista como potência autocriadora, fetichista, independente ou, em outras palavras, dissociada de seu fundamento real. $\mathrm{O}$ dinheiro alienado sob promessa de valorização futura, cuja expressão reside na fórmula D-D', oblitera toda a intermediação do processo que permite o desenvolvimento do sistema de crédito, particularmente a produção e a realização do valor cristalizado na mercadoria. Embora os juros, assim como o lucro empresarial e a renda fundiária, sejam provenientes da exploração do trabalho, seu conteúdo parece dotado de autonomia e abstraído do capital industrial.
\end{abstract}

Palavras-chave: Capital. Fetichismo. Juros.

\section{LE FETICHISME DU CAPITAL PORTEUR D'INTÉRÊT}

Résumé:

L'objectif de cet article est de montrer comme le capital porteur d'intérêt apparaît à la surface de l'économie capitaliste comme un pouvoir autocréateur, fétichiste, indépendant ou, en d'autres termes, dissocié de son fondement réel. L'argent aliéné sous la promesse d'une valorisation future, dont l'expression réside dans la formule D-D', efface toute intermédiation dans le processus qui permet le développement du système de crédit, en particulier la production et la réalisation de la valeur cristallisée dans la marchandise. Bien que l'intérêt, ainsi que le profit d'entreprise et la rente foncière, provienne de l'exploitation du travail, son contenu semble être doté d'autonomie et abstrait du capital industriel.

Mots-clés: Capital. Fétichisme. Intérêt.

1 Possui graduação em Comunicação Social com habilitação em Jornalismo pela Universidade de Fortaleza/UNIFOR (2013); bacharel em História pela Universidade Federal do Ceará/UFC (2017); bacharel em Filosofia pela Universidade Estadual do Ceará/UECE (2021); mestre em Filosofia pela Universidade Federal do Ceará/UFC (2019); licenciado em História pela Universidade Norte do Paraná (2021); doutorando em Filosofia pela Universidade Federal do Ceará/UFC (2020-2024, com período sanduíche na Université Paris-Ouest Nanterre la Défense) e membro do Grupo de Estudos Marxistas, coordenado pelo Prof. Dr. Eduardo Ferreira Chagas. Além de se dedicar ao estudo do pensamento de Marx, também tem concentrado esforços para o esclarecimento das obras de seus interlocutores, sobretudo Feuerbach e Hegel. E-mail: bruno.qcg@outlook.com.br. ORCID: https://orcid.org/00000001-6758-0597.

${ }^{2}$ Graduado em Filosofia pela Universidade Estadual do Ceará (UECE; mestre em Filosofia pela Faculdade de Filosofia e Ciências Humanas da Universidade Federal de Minas Gerais (UFMG); doutor em Filosofia pela Universität Kassel (Alemanha); pós-doutor em Filosofia pela Universität Münster (Alemanha); professor Efetivo (Associado 4) do Curso de Filosofia do Programa de Pós-Graduação em Filosofia da Universidade Federal do Ceará (UFC); professor do Programa de Mestrado Profissional em Filosofia (PROF-FILO); professor colaborador do Programa de Pós-Graduação em Educação Brasileira da FACED (UFC); bolsista de produtividade em pesquisa do CNPq (Nível 2); editor da Revista Dialectus; membro da Internationale Gesellschaft der Feuerbach-Forscher (Sociedade Internacional Feuerbach). Homepage: http://www.efchagas.wordpress.com. E-mail: ef.chagas@uol.com.br. ORCID: https://orcid.org/0000-0003-1957-6117. 
O emprego do dinheiro na economia capitalista assume uma função que supera aquela relativa a sociedades comerciais, uma vez que sua finalidade extrapola o mero intercâmbio de mercadorias ao se tornar substrato do processo de valorização do valor. "Com base na produção capitalista, o dinheiro [...] pode ser convertido em capital e, mediante essa conversão, deixar de ser um valor dado para se transformar num valor que valoriza a si mesmo, incrementa a si mesmo" (MARX, 2017, p. 385). A grandeza monetária que entra na esfera da circulação deve retornar ao seu estágio inicial com uma diferença proveniente da exploração do trabalho, de modo que o desfecho da série permita a retomada da expansão rumo ao infinito. No caso do sistema creditício, a espoliação operária é inteiramente camuflada pela mistificação do empréstimo a juros, como se o pagamento pelo capital adiantado fosse independente da forma salário.

Ponto de partida e ponto de retorno, cessão e restituição do capital emprestado, aparecem, pois, como movimentos arbitrários, mediados por transações jurídicas efetuadas antes e depois do movimento efetivo do capital e que com ele não têm relação nenhuma (MARX, 2017, p. 395).

A absorção do mais-valor em sua figura transmutada envolve agentes econômicos cujas operações pressupõem tempo de trabalho usurpado durante a produção de mercadorias, de modo que o lucro repassado às instituições financeiras após o cumprimento das metamorfoses inscritas no ciclo do capital industrial apenas demonstra a existência de uma confraria secular e predatória. A alienação impulsionada pelo reembolso valorizado se manifesta na superfície da economia burguesa como um negócio dissociado de sua base concreta. A abstração vulgar transforma o capital portador de juros numa potência autárquica, que, por estar concentrada em si mesma, aparece sem qualquer relação com o tempo de trabalho não pago. "O retorno do dinheiro às mãos do capitalista, que constitui o movimento característico do capital em geral, assume no capital portador de juros uma figura completamente exterior, separada do movimento real, do qual ele constitui a forma" (MARX, 2017, p. 395).

Embora a emissão de promissórias, letras de câmbio, títulos da dívida pública e empréstimos de todo tipo seja derivada das relações de produção capitalista, cujo âmago reside na exploração do trabalho, o negócio é mistificado pela própria natureza de seu funcionamento, de modo que um acordo mais ou menos arbitrário parece determinar a grandeza do lucro. A massa de valor alienada sob a forma dinheiro retorna ao seu possuidor com um acréscimo cujo cerne é ocultado pela ilusão que subjaz o movimento

\begin{tabular}{|l|l|l|l|l|}
\hline Qenista Dialectus & Ano 10 & n. 24 & Setembro - Dezembro 2021 & p. $164-176$ \\
\hline
\end{tabular}


do circuito usurário: “Tanto a devolução como a cessão do capital são mero resultado de uma transição jurídica entre o proprietário do capital e uma segunda pessoa. O que vemos é apenas cessão e devolução" (MARX, 2017, p. 396). O dinheiro aplicado em transações usuárias é restituído pelo seu dono à margem da produção de mercadorias, como se o procedimento fosse independente do trabalho assalariado.

Mesmo que a aquisição das forças produtivas mediante o poder social do dinheiro e a venda da mercadoria proveniente do trabalho assalariado sejam obliteradas pelo capital portador de juros, as duas operações constituem um pressuposto à acumulação monetária por meio de empréstimos recorrentes. "Os atos de circulação DM e M-D', em que a soma de valor exerce a função de dinheiro ou de mercadoria, não são mais que processos intermediários, fases do movimento total. Como capital, essa soma de valor realiza o movimento total D-D”". (MARX, 2017, p. 397).

O dinheiro empregado em operações financeiras assume o caráter de capital exatamente por ser reembolsado com mais-valor pelo seu proprietário através da cobrança de juros, portanto sua finalidade é absorver parte da riqueza usurpada pela classe dominante na esfera da produção. "É esse valor de uso do dinheiro como capital - a capacidade de engendrar o lucro médio - que o capitalista monetário aliena ao capitalista industrial pelo tempo durante o qual ele cede a este último o direito de dispor do capital emprestado" (MARX, 2017, p. 398). Caso haja um abarrotamento no mercado, a autovalorização do valor é interrompida sumariamente para desespero do credor, de modo que a união entre os agentes econômicos é desestabilizada pela falta de liquidez generalizada.

Destarte, as crises periódicas do capitalismo desmantelam o conluio arraigado na exploração do trabalho e acentua a dependência do sistema financeiro em relação à grande indústria. "O valor de uso do dinheiro emprestado consiste em poder funcionar como capital e, como tal, produzir, em circunstâncias usuais, o lucro médio" (MARX, 2017, p. 399), mas o desequilíbrio entre oferta e demanda obstrui o processo de acumulação infinita e paralisa o desenvolvimento do capital portador de juros.

O dinheiro empregado em transações creditícias apresenta uma particularidade, pois, diferente do que ocorre com as mercadorias em geral, os empréstimos com rendimentos futuros apresentam duas grandezas de valor: uma relativa ao dinheiro transformado em forças produtivas, outra equivalente ao incremento monetário sem conteúdo real. “Os juros, como preço do capital, são desde sempre uma 
expressão absolutamente irracional" (MARX, 2017, p. 401). Embora represente uma massa de valor determinada, o dinheiro, como capital portador de juros, adquire a capacidade ilusória de autogeração, cuja incoerência, entre muitas outras peculiares ao modo burguês de produção, é o duplo valor de uma mercadoria. "Uma mercadoria tem, aqui, um duplo valor: de um lado, um valor; de outro, um preço distinto desse valor, ao passo que, na verdade, o preço é a expressão monetária do valor” (MARX, 2017, p. 401).

O capital portador de juros aumenta sua quota na distribuição do lucro especialmente durante as crises, ainda que seja uma operação de risco, pois os empréstimos são motivados pela tentativa dos devedores de respeitar seus compromissos num cenário de absoluta estagnação, o que revela a escassez monetária para a quitação das dívidas junto ao sistema creditício. A metafísica da economia política clássica desmorona em virtude das leis que regem os “ciclos de rotação em que se move a indústria moderna - estabilidade, crescente animação, prosperidade, superprodução, crash, estagnação, nova estabilidade etc" (MARX, 2017, p. 407). A profissão de fé burguesa se manifesta na crença de uma igualdade entre as condições de produção e consumo bem como na certeza de valorização permanente do capital portador de juros. O movimento especulativo da produção capitalista é comprovado tanto pela falta de adequação entre oferta e demanda, ratificado pela inadimplência coletiva, como pela emissão de títulos creditícios sem lastro de pagamento.

\begin{abstract}
A taxa de juros atinge seu nível mais alto durante as crises, quando, para poder pagar, é preciso pegar dinheiro emprestado, custe o que custar. Como a alta dos juros corresponde a uma queda de preço nos papéis, isso representa uma excelente situação para que pessoas que dispõem de capital monetário possam se apropriar por preços irrisórios daqueles papéis portadores de juros, os quais tão logo a taxa de juros volte a cair, voltarão a atingir, no mínimo, seu preço médio (MARX, 2017, p. 408).
\end{abstract}

O dinheiro alienado sob a promessa de valorização futura, embora seja uma mercadoria particular em face da relação absurda entre preço e valor, é restituído pelo seu proprietário conforme as oscilações da produção capitalista, cuja superfície corresponde ao nexo inversamente proporcional entre oferta e demanda. Ainda que seja mero epifenômeno das leis que regem o processo de acumulação burguesa, o movimento do capital portador de juros é determinado pelo concerto entre os agentes econômicos.

O capital portador de juros, embora seja uma categoria absolutamente diferente da mercadoria, converte-se numa mercadoria sui generis, que tem nos juros 
seu próprio preço, o qual, tal como o preço de mercado das mercadorias comuns, é fixado em cada momento pela ação da oferta e da demanda (MARX, 2017, p. 415).

Os empréstimos que incrementam a produção de mercadorias devem ser quitados pelos seus devedores, sob condições previamente estabelecidas, com um acréscimo proveniente do tempo de trabalho não pago, de modo que o arranjo nefasto ente a grande indústria e o sistema creditício absorve mais-valor exaurindo diariamente a classe operária com inteiro reconhecimento do direito moderno. "Para o capitalista produtivo que investe capital emprestado, o lucro bruto se divide em duas partes: os juros, que ele precisa pagar ao prestamista, e o excedente sobre os juros, que forma sua própria participação no lucro" (MARX, 2017, p. 422).

A exploração do trabalho, camuflada pela autonomia ilusória do capital portador de juros, consiste no verdadeiro fundamento do processo de acumulação burguesa, do qual o lucro industrial representa apenas uma parte. "Vimos que o produto verdadeiramente específico do capital é o mais-valor, que, de maneira mais concreta, é o lucro. Para o capitalista que trabalha com capital emprestado, esse produto não é o lucro, mas o lucro menos os juros, isto é, a parte do lucro que resta para ele após o pagamento dos juros" (MARX, 2017, p. 422).

Desse modo, como um parasita dotado de inúmeras ventosas, o capital absorve a energia do hospedeiro na tentativa de garantir sua reprodução virulenta e irreprimível. As frações do lucro, particularmente o ganho empresarial ${ }^{3}$ e os juros, manifestam-se na superfície da economia burguesa como se fossem provenientes de operações distintas, sem uma raiz comum e abstraídos da exploração que lhes é constitutiva: "Uma aparece como simples fruto da propriedade do capital, a outra, como fruto da mera operação com o capital, como fruto do capital em ação ou das funções que o capitalista desempenha” (MARX, 2017, p. 424). O sistema creditício é mistificado pela economia vulgar exatamente por estar à margem da produção de mercadorias, isto é, do processo real de valorização do valor.

Os juros são, pois, a expressão do fato de que o valor - o trabalho objetivado em sua forma social geral - isto é, o valor que no processo efetivo de produção assume a forma de meios de produção, confronta-se como uma potência autônoma com a força viva de trabalho e constitui o meio para se apropriar de

\footnotetext{
${ }^{3}$ O lucro absorvido tanto pela indústria como pelo comércio a cada rotação do capital é denominado de
} ganho empresarial.

n. 24

Setembro - Dezembro 2021

p. $164-176$ 
trabalho não pago; e de que ele é esse poder na medida em que se confronta com o trabalhador como propriedade alheia. Por outro lado, na forma dos juros apaga-se essa antítese em relação ao trabalho assalariado, pois o capital portador de juros não tem como termo antagônico o trabalho assalariado, mas o capital ativo; o capitalista prestamista confronta-se como tal diretamente com o capitalista que atua de fato no processo de reprodução, mas não com o trabalhador assalariado, que se encontra expropriado dos meios de produção justamente com base na produção capitalista (MARX, 2017, p. 428).

A teoria econômica burguesa, com as ilusões que lhe são peculiares, nega a essência do sistema capitalista ao transformar o lucro em salário da classe dominante. A espoliação que garante o processo de reprodução em escala ampliada é obliterada pela tentativa absurda de conceber o enriquecimento particular sem a exploração do trabalho. Trata-se de uma "tendência apologética de apresentar o lucro não como mais-valor, isto é, não como trabalho não pago, mas como salário que o próprio capitalista recebe pelo lucro que realiza" (MARX, 2017, p. 438).

A figura metamorfoseada do mais-valor, cujas raízes sociais consistem na miséria e na exaustão dos trabalhadores, é absolutamente mistificada, e o que deveria ser "simples mais-valor, valor pelo qual não se paga equivalente nenhum, trabalho realizado e não pago" (MARX, 2017, p. 439), aparece como pagamento pelo desempenho de funções determinadas no interior da produção capitalista. O lucro, como resultado da pilhagem que mantém a progressão do valor rumo ao infinito, revela a existência de uma religiosidade profana ao glorificar a mercadoria bem como salienta o caráter nefasto da irmandade burguesa, "de maneira que o capitalista atuante explora realmente o trabalho e, quando opera com capital emprestado, divide o fruto de sua exploração em juros e lucro do empresário, que é o excedente do lucro sobre os juros" (MARX, 2017, p. 439). O fetichismo do modo burguês de produção revela sua apoteose no capital portador de juros, pois o dinheiro alienado sob promessa de valorização futura é dissociado da exploração do trabalho, de modo que o desenvolvimento do sistema de crédito se manifesta como sujeito do processo de acumulação infinita.

É no capital portador de juros que a relação capitalista assume sua forma mais exterior e mais fetichista. Aqui deparamos com D-D', dinheiro que engendra mais dinheiro, valor que valoriza a si mesmo, sem o processo mediador entre os dois extremos (MARX, 2017, p. 441).

O capital portador de juros, embora seja dotado de autossuficiência na superfície da economia burguesa, pressupõe reprodução cíclica do valor, equilíbrio entre oferta e demanda, consumo ininterrupto da mercadoria, superação da barreira que emerge 
do processo de acumulação infinita ou desenvolvimento contínuo das forças produtivas capitalistas. A restituição do dinheiro alienado sob promessa de valorização futura "é o capital consumado, a unidade do processo de produção e do processo de circulação, que, por conseguinte, gera mais-valor ao final de determinado período" (MARX, 2017, p. 441), mas a natureza holística da expansão capitalista é virtualmente decomposta pela fantasia que subjaz o circuito creditício, "e o capital aparece como fonte misteriosa e autocriadora de juros, de seu próprio incremento". A valorização do capital monetário aparece indiferente à esfera da produção, como movimento resultante da qualidade de um substrato material, inerente ao corpo do objeto. Ainda que se trate de um ser inanimado, simples coisa, sem potência e meramente simbólico, o dinheiro se transforma em sujeito do processo de acumulação usurária. "No capital portador de juros, portanto, produz-se em toda sua pureza esse fetiche automático do valor que se valoriza a si mesmo, do dinheiro que gera dinheiro, mas que, ao assumir essa forma, não traz mais nenhuma cicatriz de seu nascimento" (MARX, 2017, p. 442). A ilusão acarretada pelo cumprimento da série D-D' oblitera todo o processo de intermediação, notadamente a unidade entre produção e circulação de mercadorias, de modo que "a relação social é consumada como relação de uma coisa, o dinheiro, consigo mesma. Em vez da transformação real do dinheiro em capital, aqui se mostra apenas sua forma vazia de conteúdo" (MARX, 2017, p. 442).

Desse modo, a reprodução incrementada do dinheiro no interior do sistema creditício consiste na expressão mais desenvolvida do fetichismo burguês. Por fim, as implicações acarretadas pela distorção do movimento realizado pelo capital portador de juros podem ser resumidas nos seguintes pontos: 1) negação de um elemento constitutivo da economia burguesa, particularmente a espoliação operária; 2) dissolução da confraria profana que arruína diariamente a vida dos trabalhadores por meio do arranjo cruel entre miséria, desagregação familiar, doenças, mortes e todo tipo de mazela social; 3) autossuficiência das transações usurária em relação à produção de mercadorias.

Enquanto os juros são somente uma parte do lucro, isto é, do mais-valor que o capitalista ativo arranca do trabalhador, agora os juros aparecem, ao contrário, como o verdadeiro fruto do capital, como o originário, ao passo que o lucro, transfigurado em ganho empresarial, aparece como simples acessório e ingrediente adicionado no processo de reprodução. Aqui se completam a forma fetichista do capital e a ideia do fetichismo do capital. Em D-D', temos a forma mais sem conceito [begriffslose] do capital, a inversão e a coisificação das relações de produção elevadas à máxima potência: a forma simples do capital, como capital portador de juros, na qual ele é pressuposto a seu próprio processo de reprodução; a capacidade do dinheiro ou, conforme o caso, da mercadoria,

Ano 10 n. 24

Setembro - Dezembro 2021

p. $164-176$ 

mistificação capitalista em sua forma mais descarada (MARX, 2017, p. 442).

O equilíbrio entre produção e circulação da mercadoria, a unidade entre dois momentos inseparáveis no interior do processo de valorização do valor, é abstraído pela progressão ilusória do capital portador de juros, como se os procedimentos creditícios estivessem dissociados da exploração do trabalho e livres das perturbações que interrompem regularmente o desenvolvimento da economia burguesa. A restituição do dinheiro alienado sob promessa de valorização futura está arraigada na contradição entre trabalho e capital, na violência do consumo produtivo, na pilhagem de classe, no estranhamento social, na inversão entre sujeito e objeto ou, resumidamente, em condições materiais de existência degradantes. De todo modo, "para a economia vulgar, que pretende apresentar o capital como fonte independente de valor, de criação de valor, essa forma é naturalmente um achado magnífico" (MARX, 2017, p. 442).

Os juros, embora apareçam de modo autônomo, obliterando o germe de sua reprodução, notadamente o trabalho assalariado, representam apenas uma quota do maisvalor distribuído entre os agentes econômicos. O dinheiro empregado em transações creditícias, ao contrário do que é incutido pela mistificação burguesa, não é fonte de acumulação capitalista, pois, conforme Marx (2017, p. 443) declarou, “assim como crescer é próprio das árvores, também criar dinheiro (tokoz) [juros; descendência] parece ser próprio do capital nessa forma de capital monetário".

O sistema de crédito, embora anteceda o modo burguês de produção, assume um caráter onipresente com o desenvolvimento de uma extensa rede comercial, cujas fundações residem na economia capitalista. A realização do valor na esfera da circulação, embora seja a finalidade do processo de acumulação infinita, pressupõe a rigor letras de câmbio que fixam a liquidez em vencimentos futuros, o que já demonstra o caráter especulativo das operações de mercado. “Aqui, a única função do dinheiro é, em geral, a de meio de pagamento, isto é, a mercadoria é vendida não em troca de dinheiro, mas de uma promessa escrita de pagamento a ser realizado em determinado prazo" (MARX, 2017, p. 451). Caso os compromissos não sejam respeitados dentro dos termos contratuais, a emissão de papéis como representação de débitos ativos ocorre a contrapelo do lastro real, cujo desdobramento é a estagnação sistêmica.

A busca irrefreável do capital pela infinitude sob condições de produção e consumo absolutamente desiguais transforma o crédito em base de transações 
fraudulentas. "Negócios e especulação estão, em muitos casos, tão intimamente unidos que é impossível dizer onde exatamente acabam os negócios e onde começa a especulação" (MARX, 2017, p. 459-460). A incerteza que subjaz o processo de acumulação capitalista bem como o desespero burguês em situações de crise, retratado em demissões gigantescas, moratórias, falências e depressão geral revelam que, a despeito de suas contribuições notáveis, a economia política clássica foi incapaz de salientar a desigualdade inelutável entre oferta e demanda.

O restabelecimento do ciclo de prosperidade é garantindo, por exemplo, através da abertura violenta de novos mercados, isto é, de invasões que avançam sobre a superfície planetária destruindo sistemas produtivos independentes, aniquilando a soberania dos povos, devastando a natureza e alargando as condições de realização do valor. Conforme Marx (2017, p. 460) assinalou, “em 1843, a Guerra do Ópio abriu ao comércio inglês o mercado da China. O novo mercado ofereceria uma oportunidade para a expansão que já se encontrava em pleno auge, sobretudo a da indústria algodoeira".

Ainda que os empréstimos ocorram sob a salvaguarda de liquidez futura representada em cauções, o ciclo do capital portador de juros é absolutamente especulativo, de modo que as execuções hipotecárias apenas confirmariam a estagnação do processo de valorização do valor. O desequilíbrio que interrompe periodicamente a expansão da economia burguesa se manifestaria no sistema de crédito, por exemplo, através do desconto sumário de letras bancárias quase invariavelmente sem lastro. Se houver fundos para a quitação da dívida, o credor mais otimista ignora a explosão que cedo ou tarde afetará seus negócios; caso o débito permaneça demonstrando a fraudulência das garantias de pagamento, a crise revela sua natureza holística e arrasa a expectativa burguesa de acumulação infinita. Trata-se de um aprofundamento das incertezas que se manifestam no regime do capital desde a produção da mercadoria. Conforme Marx (2017, p. 494) declarou, “o crédito, ao permitir uma separação mais prolongada dos atos de compra e venda, serve de base para a especulação".

O desenvolvimento da economia burguesa, mais precisamente a concentração de riqueza impulsionada pelo capital portador de juros, lança as bases da desagregação produtiva que salienta o caráter metafísico da igualdade entre oferta e demanda, especialmente em virtude de barreiras tarifárias que, à revelia de um dos pressupostos mais destacados do liberalismo, obstruem o comércio entre nações e impulsionam uma tendência do processo de acumulação infinita: desequilíbrio entre as condições de 
produção e realização do valor. A disputa pelo abastecimento dos mercados exige do Estado uma política fiscal inteiramente avessa à majestade da concorrência, de modo que a arbitrariedade da mão invisível é confrontada pela proteção governamental bem como pelas complicações que lhe são decorrentes.

\begin{abstract}
A rapidez cada vez maior com que hoje se pode incrementar a produção em todos os campos da grande indústria contrasta com a progressiva lentidão da expansão do mercado para atender a essa produção aumentada. O que aquela produz em meses este só pode absorver, quando muito, em anos. Acrescentese a isso a política de proteção aduaneira, que faz com que cada país industrial se feche aos demais, especialmente à Inglaterra, aumentando assim, artificialmente, a capacidade interna de produção. Disso resulta: superprodução geral crônica, preços baixos, queda tendencial dos lucros e até mesmo sua total desaparição; em outras palavras, a tão falada liberdade de concorrência chegou ao fim da linha e se vê ela mesma obrigada a proclamar sua manifesta e escandalosa falência (ENGELS, 2017, p. 495-496) ${ }^{4}$.
\end{abstract}

A expansão das transações creditícias aprofunda a especulação comercial porque incrementa a produção de mercadorias sob condições de consumo cada vez mais estreitas. Como o movimento do capital portador de juros, assim como o processo de valorização do valor em geral, é indiferente aos embaraços acarretados pelo pauperismo, a convulsão é irreversível. Conforme Marx (2017, p. 499) declarou, "o crédito acelera ao mesmo tempo as erupções violentas dessa contradição, as crises e, com elas, os elementos da dissolução do antigo modo de produção", lançando as bases de uma agitação revolucionária. Destarte, as operações financeiras contribuem tanto para o desenvolvimento das forças produtivas como para o aumento das contradições que regem o processo de acumulação infinita.

Tais são as duas características intrínsecas ao sistema de crédito: por um lado, ele desenvolve a mola propulsora da produção capitalista, o enriquecimento mediante a exploração do trabalho alheio, até convertê-lo no mais puro e colossal sistema de jogo e fraude e limitar cada vez mais o número dos poucos indivíduos que exploram a riqueza social; por outro lado, estabelece a forma de transição para um novo modo de produção (MARX, 2017, p. 499-500).

A economia burguesa, cujo movimento é determinado pela necessidade irreprimível de superação da própria massa de valor, agrava os riscos de entupimento geral à medida que satisfaz suas necessidades internas, contudo, subordinadas ao processo de acumulação infinita, as transações usurárias estimulam a expansão capitalista independente das contradições que interrompem obrigatoriamente o ciclo de

\footnotetext{
${ }^{4}$ Trata-se aqui de um enxerto feito por Engels no decorrer da exposição de Marx sobre o papel do crédito
} na produção capitalista, portanto a referência bibliográfica para o leitor é o próprio livro III de $O$ Capital.

\begin{tabular}{|c|c|c|c|c|}
\hline Qevista Dialeatus & Ano 10 & n. 24 & Setembro - Dezembro 2021 & p. $164-176$ \\
\hline
\end{tabular}


prosperidade. O abarrotamento dos mercados, fato incontestável da especulação que subjaz o capital, é estimulado largamente pelo sistema de crédito, uma vez que o pagamento dos empréstimos é absolutamente incerto. "A caixa de Pandora da atividade especulativa de crédito tem de ser aberta, e dela sai todo tipo de coisa indesejada" (HARVEY, 2014, p. 13).

A massa de valor representada nos títulos portadores de juros é fictícia e indiferente às perturbações cíclicas da economia burguesa; sua existência, puramente nominal e alheia aos estancamentos inelutáveis processo de reprodução em escala ampliada, consiste em capitalizações que obliteram a espoliação operária. Trata-se de um procedimento que apaga "até o último rastro toda a conexão com o processo real de valorização do capital e se reforça a concepção do capital como um autômato que se valoriza por si mesmo" (MARX, 2017, p. 524). As ações, por exemplo, garantem os dividendos empresariais, isto é, transferem a seus proprietários uma quota de mais-valor a cada rotação do capital, dissociando a circulação monetária do trabalho assalariado, como se os rendimentos fossem independentes da pilhagem realizada na esfera da produção.

A autonomia dos papéis portadores de juros é confrontada necessariamente durante os períodos de estagnação, pois a desigualdade entre oferta e demanda, acarretada pelo estreitamento irreversível das condições de realização do valor, interrompe os descontos das letras de câmbio. Como resultado da falta de liquidez, "a exigência de pagamento à vista e as precauções que se observam nas vendas a crédito são particularmente características daquela fase do ciclo industrial que se segue ao crash" (MARX, 2017, p. 540). A contração do capital fictício, embora seja uma manifestação da desconfiança entre os agentes de mercado, é determinada em última instância pela superabundância de mercadorias: à medida que a economia burguesa satisfaz seu impulso vital, abreviando proporcionalmente a capacidade de consumo, maiores são os riscos de entupimento dos depósitos, moratória, falência, agitação nas bolsas e crise generalizada.

\section{A razão última de todas as crises é sempre a pobreza e a restrição ao consumo das massas em contraste com o ímpeto da produção capitalista a desenvolver as forças produtivas como se estas tivessem seu limite apenas na capacidade absoluta de consumo da sociedade (MARX, 2017, p. 541).}

O domínio da grande indústria sobre a acumulação usurária pode ser constatado durante os períodos de saturação, pois a formação de estoques gigantescos obstrui necessariamente o movimento do capital portador de juros. Indiferentes às 
condições impostas pela produção, cujos limites são determinados pela absoluta desigualdade no processo de distribuição da riqueza, os empréstimos assumem cada vez mais um caráter fraudulento. A dissociação entre compra e venda, fato independente do esforço burguês, suspende a distribuição do mais-valor entre os agentes econômicos, salienta a falta de lastro das letras de câmbio, derruba o preço das ações, aumenta o exército industrial de reserva, diminui os salários e exige do Estado medidas de intervenção que possam manter em funcionamento um sistema marcado pela contradição inelutável entre abundância e privação.

Se, portanto, os ramos de produção estão saturados e há excesso de oferta de capital de empréstimos, essa abundância de capital monetário emprestável é uma simples demonstração dos limites da produção capitalista. A fraude subsequente com base no crédito evidencia que não existe obstáculo positivo à aplicação desse capital excedente. Ela revela, no entanto, um obstáculo imposto pelas leis que regem sua valorização, pelos limites dentro dos quais o capital pode valorizar-se como capital (MARX, 2017, p. 565).

Alheio à essência antiética da economia burguesa, o crédito potencializa involuntariamente o abarrotamento dos mercados e consiste numa alavanca do próprio crash. A tendência do capitalismo a paralisações cíclicas é aprofundada por empréstimos que incrementam a produção de mercadorias independente das condições de consumo.

Os juros e o lucro comercial, embora sejam figuras transmutadas do maisvalor ou expressões da exploração do trabalho no regime do capital, são formas sociais cujas origens antecedem o nascimento do modo burguês de produção. Antes mesmo da dissociação violenta entre trabalhadores e seus meios de subsistência, do desenvolvimento de uma economia monetária e da formação do mercado mundial, já havia transações usurárias e circuitos de intercâmbio da riqueza.

As condições para o advento do crédito, independente do seu grau de desenvolvimento, residem na combinação entre produção mercantil e uso do dinheiro como meio de negócio, o que estava presente em povos da Antiguidade, como os romanos. O processo de acumulação infinita, como potência histórica dotada de legalidade interna, apenas subordinou o crédito e o comércio ao seu impulso vital, arraigado no consumo desenfreado de energia humana e forças naturais.

O capital portador de juros, ou, para empregar o termo antigo, capital usurário, figura com seu irmão gêmeo, o capital comercial, entre as formas antediluvianas do capital, que precedem por longo tempo o modo de produção 
Embora a usura esteja presente em formações pré-capitalistas, seu desenvolvimento emerge do processo de acumulação infinita, isto é, da racionalidade imanente à economia burguesa. Subordinados à autovalorização do valor, os empréstimos adquirem um caráter sistêmico e passam a incrementar regularmente a produção de mercadorias, absorvendo a cada desconto das letras de câmbio parte da riqueza proveniente da exploração do trabalho. "O sistema de crédito não significa nada além da submissão do capital portador de juros às condições e às necessidades do modo de produção capitalista" (MARX, 2017, p. 660).

A finalidade do dinheiro empregado em transações de crédito consiste na grande particularidade da alienação monetária sob o regime do capital, pois é a busca irrefreável pela extração do mais-valor que determina o sentido dos empréstimos. Conforme Marx (2017, p. 660) declarou, “mesmo quando um homem carente de meios obtém crédito como industrial ou comerciante, isso ocorre na confiança de que ele atuará como capitalista, ou seja, de que empregará o dinheiro emprestado para apropriar-se de trabalho não pago". Desse modo, o que impulsiona o movimento do capital portador de juros é o processo de reprodução em escala ampliada, cujo fundamento reside na espoliação operária.

\section{REFERÊNCIAS}

HARVEY, David. Para entender O capital: livros II e III. São Paulo: Boitempo, 2014. MARX, Karl. O Capital: crítica da economia política. Livro III. O processo global da produção capitalista. São Paulo: Boitempo, 2017. 